ШАТИЛОВ Александр Борисович - кандидат политических наук, доцент; декан факультета социальных наук и массовых коммуникаций, профессор департамента политологии Финансового университета при Правительстве РФ (125993, Россия, г. Москва, ГСП-3, Ленинградский пр-кт, 49; Absh71@yandex.ru)

\title{
«МОРАЛЬНЫЙ ИЗНОС» ВЛАСТИ КАК ФАКТОР ДЕСТАБИЛИЗАЦИИ ПОЛИТИЧЕСКИХ РЕЖИМОВ
}

\begin{abstract}
Аннотация. В статье анализируются причины «системной» и «несистемной» смены власти в современных государствах. Автор, рассматривая различные трактовки политической дестабилизации, приходит к выводу, что в основе протестных настроений современного общества лежит «моральный износ» власти, который имеет как объективные, так и субъективные причины. В частности, в статье выделяются 5 основных факторов, предопределяющих «моральный износ» власти и политического режима в целом. Кроме того, автор задается вопросом: есть ли у власти возможность предотвратить негативное развитие событий, если “моральный износ» вступил в открытую протестную стадию? С учетом мирового опыта предлагаются 3 возможные модели нейтрализации «морального износа» власти и ее политической актуализации в глазах населения.
\end{abstract}

Ключевые слова: власть, оппозиция, политический режим, «моральный износ», политический конфликт, дестабилизация, «цветные революции», элита

$\mathrm{B}$ политической науке существует масса версий и теорий относительно динамики современных политических процессов, в частности относительно дестабилизации и падения политических режимов. При этом выдвигаются несколько основных версий происходящих трансформаций.

Так, западная политическая наука, а вместе с ней и значительная часть отечественных, преимущественно либерально настроенных политологов полагает, что определяющим с точки зрения развития государств рубежа $\mathrm{XX}$ - начала XXI в. является концепт «демократический транзит». В соответствии с этой версией все «недемократические» (т.е. живущие не по западным политическим правилам) государства рано или поздно вступают на путь модернизации, при этом ориентируясь в основном на политические, социальные и экономические приоритеты США и других развитых западных стран. При этом подчеркивается, что демократический транзит должен иметь не столько спонтанный (оригинальный), сколько отраженный, копирующий характер. Эта позиция была особенно сильна в интеллектуальных кругах в 1990-е гг., когда после завершения «холодной войны» мир вступил в однополярную стадию, где основные параметры развития задавались «коллективным Западом». Как известно, американо-японский мыслитель и политолог Ф. Фукуяма в связи с такой глобальной «унификацией» даже заявил о «конце истории», т.е. фактически о полной и безоговорочной победе либерально-демократического реформаторского курса. Правда, несколько позже, в начале нулевых годов, он признал, что поторопился со своей декларацией о триумфе «свободного общества» 1 .

Конечно, определенное рациональное зерно в теории демократического транзита присутствует. В частности, нельзя не признать, что либеральные ценности зачастую являются привлекательными для современных «недемократических» обществ, поскольку обыгрывают сразу несколько популистских момен-

1 https://www.kp.ru/daily/26282/3160707/ (проверено 14.07.2020). 
тов - безграничную свободу (трактуемую как свободу от ограничений), культ потребления, демократию [Исаев 2014]. Эти достаточно простые лозунги способны мобилизовать на борьбу с «недемократическим» режимом тысячи, а то и миллионы людей. Другое дело, что после очередной «весны» или «революціі гідності» массы «неожиданно» осознают, что свобода дана лишь избранным, что для удовлетворения потребительских аппетитов нужны соответствующие финансовые ресурсы, которые крайне неравномерно распределяются в «новых демократиях», что демократия «переходного периода» (если понимать под этим термином народоправство) является либо фейковой, либо имитационной.

Другая точка зрения относительно динамики современной политики связана с геополитическим подходом к вопросам политического и социально-экономического развития современных государств. Так, значительный корпус современной российской политологической литературы посвящен анализу причин и последствий «цветных революций» и Арабской весны [Манойло 2014; 2015]. При этом в своем большинстве авторы акцентируют внимание на внешних факторах указанных событий. Бесспорно, внешняя составляющая в разрушении политических режимов Югославии, Туниса, Египта, Грузии, Украины и др. присутствует. Например, руководство США практически не скрывает тот факт, что выделило огромные суммы на подрыв стабильности на Украине в нулевых годах и на «перепрограммирование» сознания ее населения в русофобском ключе. В то же время, несмотря на все усилия Запада, до сих пор устояли враждебные Вашингтону «недемократические» режимы на Кубе, в Белоруссии, КНР, Сирии. И это при том, что вышеуказанные государства не являются закрытыми и не живут по принципу осажденной крепости.

Еще одно направление в политологии трактует происходящие революционные политические изменения (особенно в рамках Арабской весны) сквозь призму демографического фактора. Сторонники данного подхода полагают, что в странах Арабского Востока в силу целого ряда обстоятельств случился демографический взрыв, который ныне привел к «переизбытку» социально активной и политически протестной молодежи ${ }^{1}$. Соответственно, считается, что именно это «потерянное поколение», не усматривая для себя перспектив в рамках существующей политико-экономической системы, в итоге и выступило инициатором и основной движущей силой магрибских революций. Дополняют эту версию работы, трактующие Арабскую весну как «твиттерную революцию» [Русакова, Бочаров, Грибовод 2014]. Политологи и эксперты, отстаивающие данную точку зрения, полагают, что протест в арабских странах оказался таким мощным в силу соединения политической активности молодежи с «мобилизующими» сетевыми технологиями. Безусловно, определенное pro в таких трактовках имеется, тем не менее, есть и аргументы contra. Так, в Югославии, Грузии и Украине переизбыток молодежи не наблюдался (что, правда, не исключает факта активного участия 18-25-летних в свержении правящих режимов), а роль сетевых технологий в странах Арабского Востока явно преувеличена.

Таким образом, мы видим, что каждый подход имеет как свои сильные стороны, так и уязвимые позиции. Соединить их воедино, на мой взгляд, помогает понятие «моральный износ власти».

Моральный износ власти - это латентное ослабление общественной поддержки правящего политического режима, невзирая на его видимую устойчивость и прежние достижения. Именно такой моральный износ власти, на мой взгляд, являлся главным фактором дестабилизации во всех указанных выше

${ }^{1}$ https://polit.ru/article/2011/03/04/egyrev/ (проверено 14.07.2020). 
«революционных» странах, где высшее руководство оказалось явно не готовым к резкой смене общественных настроений и симпатий.

Когда наступает и в чем выражается моральный износ власти?

Несмотря на то что общество в современных государствах (даже демократических) находится в достаточно жестком подчинении (явном или подспудном) у правящих элит, практика показывает, что фактор общественной поддержки не стоит сбрасывать с политических счетов. Правда, в отличие от XX столетия, современное общество самостоятельно не способно выступить инициатором смены власти - с одной стороны, в силу своей относительной политической пассивности и гедонизма, с другой - в силу наличия у правящего класса эффективных технологий пресечения и подавления открытого протеста. В то же время накопление в обществе претензий к власти способно создать необходимую почву для политической дестабилизации. Подобными «благоприятными» условиями могут воспользоваться как зарубежные, так и внутренние противники власти.

Так, например, опираясь на подспудное недовольство украинского общества коррумпированным режимом В. Януковича и волюнтаризмом «донецкого клана», «западникам» удалось поднять «массы» на Майдан 2014 г., а в Ливии моральный износ власти М. Каддафи привел к восстанию против него контрэлитных сил, получивших далее финансовую и силовую поддержку США и Евросоюза.

Итак, какие факторы предопределяют моральный износ власти и политического режима в целом?

Первый фактор - длительность пребывания у рычагов управления страной одного и того же лидера и его команды. Как только политик избирается главой государства и формирует вокруг себя «управленческий пул», с этого времени начинается отсчет его морального износа, даже если на тот момент он еще является популярной и авторитетной персоной. Более того, чем выше ожидания от избранного лидера, тем быстрее идет деградация его имиджа в глазах населения. Дело в том, что народ, поддерживая того или иного политика, вольно или невольно наделяет его сверхъестественными мифологическими качествами и ждет от него перманентных «чудес». Само собой, даже самый эффективный руководитель не может в одночасье, а тем более постоянно удовлетворять ожидания охлоса. В результате практически неизбежно его рекордные поствыборные рейтинги падают и могут восстановиться и даже прибавить (как это было с В.В. Путиным в «тучные нулевые») только в случае последующих заслуг и достижений. Однако в любом случае солидный «возраст» власти ведет к снижению ее популярности в обществе, а примелькавшиеся лица политиков вызывают все меньше энтузиазма у населения. Такого рода моральный износ характерен для всех политических режимов, не только для тоталитарных и авторитарных, но и для демократических. Зачастую он затрагивает даже персон с мировой известностью. Чего стоит только явно преждевременный уход с публичной политической арены таких «тяжеловесов», как Ш. де Голль и У. Черчилль. Их проблема во многом заключалась в том, что современникам хотелось обновить власть, увидеть там «новые лица», «поэкспериментировать»с политическим кадровым резервом. Нечто подобное произошло на президентских выборах в США в 2016 г., когда «простой люд» из «ржавого пояса» (не без помощи специфической избирательной системы) сломал «либеральный» тренд в американской политике, прокатив фаворита - Х. Клинтон и отдав предпочтение «свежему» политику-популисту Д. Трампу.

Не факт, что такое политическое экспериментаторство общества всегда является удачным, но оно объективно отражает «прогрессистский» характер поли- 
тической жизни современного человечества. Маховик динамики и перманентных трансформаций, запущенный еще в XIX в., не только не снижает обороты, но, напротив, лишь набирает темпы. Соответственно, «лаг» спокойствия и безмятежного существования у команды, пришедшей во власть, весьма небольшой, далее ей необходимо демонстрировать исключительное мастерство, чтобы удерживать общественные симпатии. При этом правящую элиту не должно успокаивать отсутствие сильной оппозиции. Зачастую при дефиците политической конкуренции голосование населения за власть на выборах разного уровня является инерционным, что ошибочно трактуется как объективная поддержка правящего курса со стороны электората. Тем горше оказывается разочарование власти, когда неблагодарные (иногда в прямом смысле этого слова) граждане с энтузиазмом воспринимают «внезапное» появление несистемной оппозиции и забывают о своих прежних кумирах. В этом плане вполне показательна история СССР 1980-х гг. Пока в Советском Союзе существовал внутриэлитный политический консенсус, не было официально разрешенной оппозиции, а население почти стопроцентно голосовало за «нерушимый блок коммунистов и беспартийных» на безальтернативных выборах, у руководства компартии сохранялась иллюзия всенародной поддержки. Однако, когда режим просел, а в правящей элите произошел раскол, казалось бы, незыблемые позиции КПСС обрушились практически моментально. И опять же во многом это стало следствием слишком долгого 70-летнего правления коммунистов (как бы ни оценивать результаты их деятельности). Граждан СССР потянуло «на новенькое». А ввиду того, что КПСС являлась «стержнем» всей советской системы, то ее исчезновение автоматически повлекло сперва крах политического режима, а затем и всей советской государственности.

Второй фактор морального износа власти - раскол правящей элиты. Как показывает практика, даже самый непопулярный режим при наличии консолидированной элиты способен выдержать самые мощные политические перегрузки. Так было в Российской Федерации в 1992-1999-х гг, когда лишь внутриэлитный консенсус позволил Б.Н. Ельцину удержать ситуацию под контролем в условиях системного политического и социально-экономического кризиса и обеспечить «плавную» передачу власти В.В. Путину. Другой пример - современная Сирия, где «правящий класс» сплотился вокруг Б. Асада и оказал упорное сопротивление комплексному давлению со стороны ИГИЛ (организация, запрещенная в РФ) и Запада.

Нечто подобное наблюдалось и в Китае на рубеже 1980-1990-х гг. Лишь политическая воля Дэн Сяопина и сплоченность партийного руководства КПК обусловили поражение «бархатной революции» на площади Тяньаньмэнь даже в атмосфере морального износа власти и ортодоксальной коммунистической идеологии.

В то же время раскол правящей политико-экономической верхушки привел к падению политических режимов С. Милошевича, Х. Мубарака, В. Януковича.

Кстати, и падение СССР во многом приблизил раскол внутри КПСС, где уже в период правления Л.И. Брежнева возникло острое соперничество как между идеологическими фракциями (консерваторы, либералы, сталинисты, почвенники), так и различными поколениями партийно-хозяйственной и силовой элиты.

С учетом изложенного выше можно отметить один любопытный и универсальный момент. Идеологическая и номенклатурная многосоставность элиты является плюсом в спокойные, некризисные периоды существования политических режимов, поскольку такой плюрализм позволяет проводить гибкую и сбалансированную политику. Когда же наступают кризисные времена, много- 
составность элиты трансформируется в ее рыхлость и становится дополнительным фактором политической дестабилизации.

Внутриэлитный раскол чаще всего происходит в странах с неустоявшейся политической системой. Если брать ведущие страны Запада, где истеблишмент давно уже стал наследственным, фундаментальные конфликты в его рядах практически невозможны. В этом плане показателен опыт США, где победа Д. Трампа в 2016 г. была воспринята как «крушение основ» разве что рядовыми гражданами, в то время как элита сохранила спокойствие, резонно полагая, что новый президент просто будет вынужден играть по общепринятым правилам, что в принципе и произошло. Хотя при этом на всякий случай американская элита подстраховалась от несистемного поведения хозяина Овального кабинета угрозой импичмента по делу «русских хакеров», а потом еще и перехватом у республиканцев Палаты представителей в ноябре 2018 г.

Третий фактор морального износа политического режима - идеологический и мировоззренческий кризис. Особенно это касается государств, где господствует моноидеология. При всей актуальности и успешности в начале своего пути, она неизбежно устаревает и деградирует, ее воздействие на общество постепенно снижается, ну а затем она теряет не только свою «сакральность», но и привлекательность. Так было, например, в 1970-1980-х гг. в СССР, где искренняя приверженность коммунистической догматике стала восприниматься обществом с иронией, а позже вообще стала считаться «неприличной». И это при том, что в 1920-1960-х гг. коммунистическая идея воспринималась даже интеллектуальной частью советского общества как «единственно верная» и «передовая».

Четвертая причина морального износа политического режима - социальноэкономическая алчность граждан, которые нередко оказываются втянутыми в потребительскую «воронку», ожидая от власти регулярных бонусов и преференций. При этом, даже получая такие «подарки», население не удовлетворяется достигнутым и выдвигает власти все новые, повышенные требования. Таким образом, создается ситуация, весьма опасная с точки зрения политической стабильности: постепенно граждане привыкают шантажировать руководство страны формулой: «лояльность в обмен на преференции». С учетом того, что ресурсный потенциал у государства небезграничен, моральный износ власти также подпитывается неутолимым социальным аппетитом народных масс. Причем эта причина ослабления доверия к власти со стороны общества характерна как для устоявшихся, так и для «хрупких» политических систем. Самый показательный пример - Ливия времен М. Каддафи, где политический режим обеспечил гражданам едва ли не «коммунистический» образ жизни по принципу: «от каждого по способностям, каждому по потребностям». Вот некоторые факты:

- бензин стоил дешевле воды: 1 литр бензина - 0,14 долл.;

- новобрачным выплачивалось 64000 долл. на покупку квартиры;

- образование и медицина были полностью бесплатными;

- на каждого члена семьи государство выплачивало в год 1000 долл. дотаций;

- пособие по безработице составляло 730 долл.;

- зарплата медсестры - 1000 долл.;

- за каждого новорожденного выплачивалось 7000 долл.;

- на открытие личного бизнеса предоставлялась единовременная материальная помощь в 20000 долл.;

- крупные налоги и поборы были запрещены;

- ВВП на душу населения составлял 14192 долл.;

- образование и стажировка за рубежом осуществлялись за счет государства; 
- существовала сеть магазинов для многодетных семей с символическими ценами на основные продукты питания;

- часть аптек обеспечивала бесплатный отпуск лекарств;

- квартирная плата отсутствовала;

- плата за электроэнергию для населения отсутствовала;

- кредиты на покупку автомобиля и квартиры были беспроцентными;

- покупку автомобиля до 50\% оплачивало государство, бойцам народного ополчения $-65 \%$.

Кроме того, за 40 лет правления М. Каддафи население Ливии выросло в 3 раза, при этом детская смертность уменьшилась в 9 раз, а продолжительность жизни в стране увеличилась с 51,5 до 74,5 лет 1 .

Пятая причина морального износа власти - снобизм элиты и минимизация искреннего диалога между властью и обществом. Дестабилизирующим фактором является отрыв правящего класса от народа и открытая демонстрация им своего привилегированного положения. Такого рода поведение представителей истеблишмента даже в условиях политического «штиля» и социально-экономической стабильности влечет за собой негодование «простого люда» и активизацию оппозиции. Что же говорить о периодах общественно-политических потрясений и кризисов! В последнем случае факты вызывающих и некорректных действий людей, облеченных властью, а также их неосторожные, а тем более, хамские высказывания служат основанием для негативной обработки общественного мнения как со стороны внутренних противников режима, так и со стороны внешних недругов. В качестве примера можно привести спекуляции насчет золотого унитаза и золотого «батона» Виктора Януковича в преддверии Майдана № 2, а также волну критики российской власти со стороны общественности в 2018 г. за высокомерные высказывания ряда чиновников ${ }^{2}$. Кстати, опасность «чиновного хамства» была признана серьезной угрозой стабильности и российским руководством. Недаром в 2020 г. в Госдуму был внесен (а в июле 2020 г. принят в первом чтении) закон, карающий представителей власти за оскорбление граждан ${ }^{3}$. Кроме того, за проявленное высокомерие в отношении простых россиян высокопоставленные руководители стали лишаться своих постов по административной линии (в качестве примера можно привести главу Чувашии Михаила Игнатьева, отправленного в отставку с формулировкой «в связи с утратой доверия» $)^{4}$.

Как бы то ни было, но при определенных условиях неэффективные и противоречивые действия легальной власти приводят к ситуации ее морального износа, за которым чаще всего следуют революционные события. В этих условиях возникают еще вопросы: всегда ли моральный износ приводит к свержению правящего политического режима и что последний должен делать, чтобы избежать катастрофы? В принципе есть несколько эффективных вариантов действий власти для того, чтобы переломить ситуацию в свою пользу.

Первый вариант - репрессивный. Он заключается в жестком подавлении активности несистемной оппозиции (вплоть до массовых расстрелов и физической ликвидации лидеров протеста). Успешным примером этого рода являются действия властей КНР по пресечению революционного сценария в 1989 г. на площади Тяньаньмэнь. Тогда в результате применения силы для разгона оппозиционеров погибли от нескольких сот до нескольких тысяч человек,

\footnotetext{
1 http://plainnews.ru/pub-2.html (проверено 14.07.2020).

2 https://fishki.net/anti/2792352-itogi-2018-goda-top-20-citat-rossijskih-chinovnikov. html (проверено 14.07.2020).

3 https://tass.ru/obschestvo/8905283 (проверено 14.07.2020).

4 https://www.kp.ru/daily/27091.4/4163468/ (проверено 14.07.2020).
} 
также несколько тысяч человек были казнены позже по итогам показательных судебных процессов 1 . Однако, проявив жесткость, китайские власти параллельно попытались «задобрить» граждан политическими и экономическими реформами. Безжалостно разгромив прозападную оппозицию, лидеры КНР вполне справедливо не стали заниматься тоталитарным «реставраторством», a, напротив, предложили обществу достаточно привлекательный проект инновационного пути обновления страны на основе реализации смешанной планово-рыночной модели экономики. Одновременно была несколько смягчена архаичная коммунистическая догматика - ее существенно «разбавили» идеями китайского патриотизма и конфуцианства как более близкими «рядовому китайцу».

Однако в рамках первого варианта преодоления своего морального износа власти разных государств мира чаще всего идут по пути наименьшего сопротивления. Сбив натиск непримиримой оппозиции и временно загнав ее в подполье, политический режим продолжает прежнюю политику, возвращая все на круги своя. Такая позиция власти может быть следствием либо переоценки своих сил и возможностей, либо понимания конечности своего правления (по принципу: «после нас хоть потоп»). Например, последняя позиция была характерна для политического режима Зимбабве в последние годы президентства Р. Мугабе. Он, опираясь на голую силу, регулярно отменял неудачные для себя результаты выборов и репрессировал оппонентов. При этом Мугабе даже не пытался маневрировать и имитировать изменения в соответствии с запросом основной части зимбабвийского общества.

Вторую модель реакции власти на свой моральный износ можно назвать превентивной. Она предполагает достаточно прагматичное понимание лидером и элитой страны политических реалий и общественных настроений. Соответственно, выявив на ранней стадии симптомы начинающегося «износа», политический режим начинает активное лавирование с целью снятия протестных настроений и актуализации собственной политической и социальноэкономической повестки. Нечто подобное мы видели в 2008-2012 гг. в РФ, когда руководство страны путем кадровых рокировок (операция «Преемник») и выдвижения новых идей (проект инновационного развития России) сумело не просто преодолеть симптомы морального износа и «перезагрузиться», но и, более того, в очередной раз отмобилизовать российское общество в рамках «крымского консенсуса» [Шатилов 2015]. Нечто подобное мы видели и в 2020 г., когда российской власти удалось «перебить» распространение латентных оппозиционных настроений путем запуска конституционной реформы.

Наконец, третью модель можно назвать отвлекающей. В этом случае власть стремится переключить внимание общества с внутренних политических и социально-экономических проблем на иные, чаще всего внешние «раздражители». Одним из примеров такого рода является тактическая схема «маленькой победоносной войны», которую используют многие «морально устаревшие» режимы для собственной «актуализации». Причем для нестатусных государств такая политика чревата колоссальными рисками. Так, например, стремление «взбодрить» общество войной за Фолклендские (Мальвинские) острова завершилось для аргентинской хунты не только военным, но и политическим поражением. Нечто подобное имело место и в 2008 г., когда, находясь в ситуации морального износа, М. Саакашвили предпринял силовую авантюру в Южной Осетии, которая опять же привела его не только к потере двух непризнанных республик, но

${ }^{1}$ https://www.rfa.org/mandarin/zhuanlan/wangdanreyou/wd-11302009104315.html (проверено 14.07.2020). 
и президентского кресла. В то же время тактику «малой победоносной войны» вполне могут использовать геополитические «тяжеловесы». В частности, подобным образом вели себя власти США в конце XX - начале XXI в. Пользуясь своим военно-политическим и экономическим доминированием, они провели ряд подобных операций. Их войны в Югославии, Афганистане, Ираке, Ливии носили в т.ч. «социально отвлекающий» характер, побуждая рядовых американцев сплотиться вокруг власти перед лицом «сербского великодержавного шовинизма» или «международного терроризма». Тем не менее даже успешные войны не гарантируют автоматического преодоления морального износа. Так, победив югославское руководство в 1999 г., Демократическая партия США проиграла выборы 2000 г. республиканцам. Нечто подобное произошло в 2016 г., когда американские демократы не смогли конвертировать серию успешных «цветных революций» в электоральную победу, достаточно неожиданно проиграв Д. Трампу. Можно констатировать, что отвлекающая модель чаще всего позволяет лишь оттянуть момент морального износа, а иногда просто загоняет болезнь внутрь.

Таким образом, моральный износ власти является очень серьезной угрозой с точки зрения стабильности современных политических режимов. Подспудный общественный протест, вызревший внутри вследствие целого ряда факторов, может привести к резкому всплеску политической конфликтности и даже крушению внешне вполне устойчивых режимов.

\section{Список литературы}

Исаев Б.А. 2014. Принцип домино и цепи революций: где, почему и как случаются «цветные революции». - Конфликтология. № 2. С. 43-63.

Манойло А.В. 2014. Роль цветных революций в демонтаже современных политических режимов. - Национальная безопасность. № 3(32). С. 406-414.

Манойло А.В. 2015. Цветные революции и технологии демонтажа политических режимов. - Мировая политика. № 1. С. 1-19.

Русакова О.Ф., Бочаров А.В., Грибовод Е.Г. 2014. Концептуальные основания стратегии цветной революции: теории soft power, управляемого хаоса и медиатизации политики. - Социум и власть. № 4(48). С. 42-47.

Шатилов А.Б. 2015. «Крымский консенсус» российской элиты: причины и последствия. - Гуманитарные науки. Вестник Финансового университета. 2015. № 2. С. 6-13.

\section{MORAL DETERIORATION OF THE POWER AS A FACTOR OF DESTABILIZATION OF POLITICAL REGIMES}

Abstract. The article analyzes the causes of the systemic and non-systemic change of power in modern states. The author, considering various interpretations of political destabilization, concludes that the protest mood of modern society is based on the moral deterioration of power, which has both objective and subjective reasons. In particular, the paper identifies five main factors that determine the moral deterioration of power and the political regime as a whole.

In addition, the author raises the question: does the government have the opportunity to prevent the negative development of events if the moral deterioration has entered an open protest stage? Therefore, based on international experience, the author 
proposes three possible models to neutralize the moral deterioration of power and realize its political actualization among the population.

Keywords: power, opposition, political regime, moral deterioration, political conflict, destabilization, color revolutions, elite

УСМАНОВА Заира Романовна - кандидат политических наук, доцент департамента политологии факультета социальных наук и массовых коммуникаций Финансового университета при Правительстве РФ (125993, Россия, г. Москва, ГСП-3, Ленинградский пр-кт, 49; ZRUsmanova@fa.ru) ШАШЕНКОВ Александр Олегович - аспирант департамента политологии факультета социальных наук и массовых коммуникаций Финансового университета при Правительстве РФ (1255993, Россия, г. Москва, Ленинградский пр-кт, 49; AOShashenkov2019@edu.fa.ru)

ВОРОПАНОВ Сергей Александрович - аспирант департамента политологии факультета социальных наук и массовых коммуникаций Финансового университета при Правительстве РФ (1255993, Россия, г. Москва, Ленинградский пр-кт, 49; SAVoropanov2019@edu.fa.ru)

\title{
РИСКИ РЕФОРМИРОВАНИЯ ГОСУДАРСТВЕННОЙ СОЦИАЛЬНОЙ И ЭКОНОМИЧЕСКОЙ ПОЛИТИКИ В СОВРЕМЕННОЙ РОССИИ
}

\begin{abstract}
Аннотация. В статье представлены результаты исследования, проведенного группой молодых ученых в рамках проекта «Социально-экономическое неравенство в России: тенденции и адаптация успешных зарубежных практик по преодолению/смягчению бедности». Часть исследования посвящена проблемам реформирования государственной социальной и экономической политики в России, а также возможностям преодоления негативных практик. Предложенные в статье группы факторов риска выявлены и заложены в компаративную матрицу, позволяющую качественно оценить взаимосвязь и взаимозависимость социальных, экономических, политических, правовых, демографических, экологических, информационных трансформаций. Составленная авторами схема характеризуется аналитическим синергизмом и эмерджентностью. В качестве выводов установлено, что большинство рисков находятся в состоянии взаимовлияния и взаимозависимости. В связи с этим социально-экономические меры должны быть гармонизированы и сращены практически со всеми направлениями деятельности государства.
\end{abstract}

Ключевые слова: бедность, социальная эксклюзия, социальная политика, экономическая политика, политические реформы, риски.

Актуальность исследования. В Указе Президента РФ «О национальных целях и стратегических задачах развития Российской Федерации на период до 2024 года» в качестве одной из национальных целей обозначено двукратное снижение бедности ${ }^{1}$. Проблема бедности и значительного разрыва в доходах беднейших и богатейших слоев общества актуальна практически во всех странах мира. Большинство из них во главу национальной политики ставят цели экономического развития и построения социального государства. Существуют как умеренные, так и радикальные прогнозы, по которым природные, техногенные, гуманитарные катастрофы и эпидемии, а также последующие за ними эконо-

1 Указ Президента РФ от 07.05.2018 № 204 «О национальных целях и стратегических задачах развития Российской Федерации на период до 2024 года». Доступ: http://kremlin. ru/acts/bank/43027 (проверено 12.06.2020). 